Jian Wang • Susan Near • Kue Young

Philip W. Connelly • Robert A. Hegele

\title{
ABCC6 gene polymorphism associated with variation in plasma lipoproteins
}

Received: July 24, 2001 / Accepted: September 4, 2001

\begin{abstract}
The ATP cassette-binding (ABC) gene superfamily contains more than 40 members, many of which are involved in cellular lipid transport. The most prominent example is $A B C A 1$, mutations in which affect plasma high-density lipoprotein (HDL) cholesterol concentration. $A B C C 6$ is another member of the $\mathrm{ABC}$ gene family, and mutations in $A B C C 6$ were recently shown to cause pseudoxanthoma elasticum (PXE). A Canadian patient with PXE was referred for assessment of moderately severe type IV hyperlipoproteinemia with hypoalphalipoproteinemia, which was refractory to pharmacological treatment. We identified intron-exon boundaries of $A B C C 6$ to sequence genomic DNA from this patient to find the disease mutation. We report (1) identification of a set of amplification primers for the 31 exons of $A B C C 6$; (2) identification of the $A B C C 6 \mathrm{R}>\mathrm{X} 1164$ nonsense mutation in the PXE subject with dyslipidemia; (3) identification of common amino acid variants and silent nucleotide variants in $A B C C 6$, with a range of allele frequencies across ethnic groups; (4) evidence consistent with a possible pseudogene encoding 9 exons with sequence homology to $A B C C 6$; and (5) association of the $A B C C 6 \mathrm{R}>\mathrm{Q} 1268$ variant with plasma triglyceride and HDL cholesterol. The results suggest that $A B C C 6$ may be a determinant of plasma lipoproteins.
\end{abstract}

Key words Multidrug resistance $\cdot$ Genomic DNA · Complex traits $\cdot$ Atherosclerosis $\cdot$ Metabolism

J. Wang $\cdot$ S. Near $\cdot$ R.A. Hegele $(\bowtie)$

Blackburn Cardiovascular Genetics Laboratory, Robarts Research

Institute, 406-100 Perth Drive, London, ON N6A 5K8, Canada

Tel. +1-519-663-3461; Fax +1-519-663-3789

e-mail: robert.hegele@rri.on.ca

K. Young

Northern Health Research Unit, Department of Community Health Sciences, University of Manitoba, Winnipeg, MB, Canada

P.W. Connelly

St. Michael's Hospital, University of Toronto, Toronto, ON, Canada

\section{Introduction}

Mutations in the gene encoding ATP-binding cassette transporter 1 (ABCA1) cause Tangier disease (TD) and familial deficiency of high-density lipoprotein (HDL) cholesterol (Bodzioch et al. 1999; Brooks-Wilson et al. 1999; Rust et al. 1999; Remaley et al. 1999; Brousseau et al. 2000; Wang et al. 2000). There is also some evidence that a common variation in $A B C A 1$ may be a determinant of plasma lipoprotein concentration (Wang et al. 2000; Clee et al. 2001). $A B C A 1$ is part of a multigene family comprising more than $40 \mathrm{ABC}$ transporters, many of which transport a variety of lipids, including cholesterol, phospholipids, bile acids, and very long chain fatty acids (Klucken et al. 2000). Two other members of the ABC transporter family, namely $A B C G 5$ and $A B C G 8$, were recently shown to play a crucial role in sterol absorption through their implication as causative genes for sitosterolemia (Berge et al. 2000; Lee et al. 2001). In addition, expression of several members of the $\mathrm{ABC}$ multigene family is regulated by lipoproteins (Klucken et al. 2000). These attributes of the ABC multigene family - their implication as determinants of lipoproteins, general involvement in the absorption and transport of lipids, and regulation in vitro by HDL suggests that other family members could be involved in plasma lipoprotein variation. In this regard, the presence of HDL cholesterol abnormalities in patients with mutations in other members of the $\mathrm{ABC}$ multigene family might justify the study of other family members as determinants of plasma lipoprotein traits.

Pseudoxanthoma elasticum (PXE; autosomal recessive OMIM 264800 and autosomal dominant OMIM 177850) is an inherited systemic disorder affecting the connective tissue, and is characterized by progressive calcification of the elastic fibers of the eye, skin, and vasculature (Neldner 1988). Patients typically have decreased visual acuity, characteristic skin lesions, and peripheral vascular disease (Neldner 1988). Recently, missense, nonsense, and splice site mutations in the ABCC6 gene (OMIM 603234) were found to cause autosomal recessive, autosomal dominant, 
and sporadic forms of PXE (Le Saux et al. 2000; Bergen et al. 2000; Ringpfeil et al. 2000, 2001). ABCC6 (OMIM 603234), also called MRP6, encodes a 1503-amino acid plasma membrane protein with a molecular weight of $165 \mathrm{kD}$ and 17 membrane-spanning helices grouped into three transmembrane domains (Le Saux et al. 2000; Bergen et al. 2000; Ringpfeil et al. 2000). Although the ABCC6 product likely transports xenobiotics, the physiological targets are not known.

Cross-sectional studies involving relatively large numbers of PXE patients indicate a higher-than-expected prevalence of hypertriglyceridemia (Neldner 1988) and depressed plasma HDL cholesterol (Renie et al. 1984) compared with age- and sex-matched control subjects. Our interest in $A B C C 6$ as a candidate gene for plasma lipoproteins was kindled by the observation of long-standing refractory dyslipidemia - elevated triglycerides and low HDL cholesterol - in a patient with autosomal recessive PXE. To find the ABCC6 mutation in this PXE subject, we defined a set of genomic DNA amplification primers for most of the $A B C C 6$ coding sequence. We found that our PXE subject with dyslipidemia was homozygous for a premature truncation mutation in $A B C C 6$. We also found several common variants in $A B C C 6$, allowing for assessment of association of variation at this locus with plasma lipoproteins.

\section{Subjects and methods}

\section{Subjects}

$P X E$ subject. The index patient, an orphan, was diagnosed with PXE as a child on the basis of characteristic skin findings affecting his neck, chest, and flexor regions of both extremities, in addition to the typical bilateral angioid retinal changes, which were more pronounced in the right eye. $\mathrm{He}$ was diagnosed with dyslipidemia at 30 years of age. Untreated plasma concentrations of total cholesterol, triglyceride, low-density lipoprotein (LDL) and HDL cholesterol (mean \pm SD from three determinations) were $5.07 \pm$ $1.23 \mathrm{mmol} / \mathrm{L}, 4.88 \pm 3.76 \mathrm{mmol} / \mathrm{L}, 2.56 \pm 1.17 \mathrm{mmol} / \mathrm{L}$, and $0.56 \pm 0.33 \mathrm{mmol} / \mathrm{L}$, respectively, consistent with moderate type IV hyperlipidemia with hypoalphalipoproteinemia. He received dietary and lifestyle advice, and drug treatment, which included fibric acid derivatives, 3-hydroxy-3methylglutaryl coenzyme A (HMG CoA) reductase inhibitors, and combinations of these drugs at various times. The most normal triglyceride and HDL cholesterol concentrations while on treatment were $1.88 \mathrm{mmol} / \mathrm{L}$ and $0.76 \mathrm{mmol} /$ $\mathrm{L}$, respectively, despite excellent compliance. Plasma triglycerides and HDL cholesterol had not been within the reference range for age and sex since treatment began.

FHA subjects. We selected from our dyslipidemia archives eight subjects who each conformed to biochemical criteria for heterozygous familial hypoalphalipoproteinemia (FHA), namely, plasma HDL cholesterol and/or apolipoprotein (apo) AI concentration below the fifth per- centile for age and sex, with plasma triglyceride concentration below the fiftieth percentile for age and sex. None of these subjects had any physical manifestations compatible with PXE or TD. These subjects had all been shown to have normal sequences for the APOA1, LCAT, and ABCA1 genes encoding apo AI, lecithin:cholesterol acyl transferase, and ABC-1, respectively.

Control samples. Samples from normolipidemic subjects taken from six ethnic groups (38 Europeans, 44 Oji-Cree, 30 Inuit, 36 Africans, 37 Chinese, and 38 South Asians) were studied to determine allele and genotype frequencies.

Inuit sample for lipoprotein association. For this analysis, we studied normolipidemic Canadian Inuit (Hegele et al. 1997). Briefly, 516 randomly selected individuals 18-80 years of age participated; of these, 281 reported themselves as being Inuit, 112 as being of mixed ethnic background, 92 as being of European background (white), and 31 as being of an ethnic background other than Inuit, mixed, or white. Blood samples were obtained with informed consent. The first exclusion criterion was a self-reported non-Inuit ancestry. The second exclusion criterion was an inadequate blood sample for genetic determinations, which left 216 subjects for the association analysis.

Determining the intron-exon boundaries of $A B C C 6$

Genomic DNA was isolated from the whole blood of all study subjects using an established method (Puregene, Gentra Systems, Minneapolis, MN, USA). We used our established method to determine intron-exon boundaries of $A B C C 6$ (Wang et al. 2000). Human ABCC6 sequence information was obtained from human chromosome 16 genomic bacterial artificial chromosome (BAC) clone CIT987SK-A962B4 (GenBank accession number U91318) and human ABCC6 cDNA sequence (GenBank accession number NM_001171). Once the intron-exon boundaries were determined, the $A B C C 6$ gene-coding region could be sequenced using polymerase chain reaction primers designed to amplify the genomic region containing each individual exon, the intron-exon boundaries, and $>50 \mathrm{bp}$ of intronic sequence. In addition, the primers were chosen to share an optimum annealing temperature of $59^{\circ} \mathrm{C}$ (Table I), which allowed for optimal use of a single amplification apparatus.

\section{$A B C C 6$ genomic mutations and polymorphisms}

Samples from nine subjects were analyzed extensively: the PXE subject and the eight subjects with FHA described earlier. Direct genomic DNA sequencing of the individual exons was carried out using the primers in Table I. All amplification reactions were carried out in a 50- $\mu$ l mixture containing $32 \mathrm{pmol}$ of each primer, $0.2 \mathrm{mM}$ each of deoxyadenosine triphosphate, deoxycytidine, triphosphate, deoxyquanosine triphosphate, and deoxythymidine triphosphate, $1.5 \mathrm{mM} \mathrm{MgCl}_{2}, 50 \mathrm{mM} \mathrm{KCl}, 20 \mathrm{mM}$ Tris $\mathrm{HCl}$ (pH 8.4), and 2.5 U Taq Platinum DNA polymerase (GIBCO BRL, Life Technologies, Mississauga, ON, Canada). Each amplifi- 
Table 1. Primer sequences to amplify coding regions of $A B C C 6$

\begin{tabular}{|c|c|c|}
\hline Exon & Primer sequence $5^{\prime}$ to $3^{\prime}$ & $\begin{array}{l}\text { Product } \\
\text { size (bp) }\end{array}$ \\
\hline \multirow[t]{2}{*}{1} & F: GAGACTTAGCGACAGACAGAC & \multirow[t]{2}{*}{142} \\
\hline & R: TCTGCAGCCAAACCAAGCCTG & \\
\hline \multirow[t]{2}{*}{2} & F: CTGCCTTGTACCATCСТАAGG & \multirow[t]{2}{*}{225} \\
\hline & R: CATTGCCTGGTTCCAGGCTC & \\
\hline \multirow[t]{2}{*}{3} & F: GCCTACCAGTTTGCTGTGAC & \multirow[t]{2}{*}{259} \\
\hline & R: TTGTTCTCCACTGTGGCAGG & \\
\hline \multirow[t]{2}{*}{4} & F: TTGCCTGCCACAGTGGAGAAC & \multirow[t]{2}{*}{344} \\
\hline & R: GACTGGCTTGTGTGTGTCAC & \\
\hline \multirow[t]{2}{*}{5} & F: AGAACCACTAGGAAAGCCAGG & \multirow[t]{2}{*}{321} \\
\hline & R: GAGACCTCAAAGTGGAACAGG & \\
\hline \multirow[t]{2}{*}{6} & F: CACAGTTCGTCCTGTCTTCC & \multirow[t]{2}{*}{268} \\
\hline & R: CGAAGAAGAAAGCACTGAGGC & \\
\hline \multirow[t]{2}{*}{7} & F: TGACTTACCCAGGGTCACAC & \multirow{2}{*}{268} \\
\hline & R: TCTGAAGTAGCATCAGGTGAG & \\
\hline \multirow[t]{2}{*}{8} & F: GCCTCTTAAGTGGGTACTCAG & \multirow[t]{2}{*}{482} \\
\hline & R: GCACCAGATGTATAGGCAGAG & \\
\hline 9 & F: CGACTGATCCTCCACATCTG & 368 \\
\hline & R: TGAATGCGTTCTCAGCTGCTG & \\
\hline 10 & F: GAGAGGTTGGCCTAAGAGAC & 417 \\
\hline & R: CTCTTCCAGCCTCTTGAATGC & \\
\hline 11 & F: GACCTCCTATCTCATCCTGTG & 401 \\
\hline & R: GCAGCTCACAGACGACAAGA & \\
\hline 12 & F: TTGCTGAAGGGTGGCTGTCA & 419 \\
\hline & R: GAACAGGATCCAGAATGAGTG & \\
\hline 13 & F: AGGCTGCCCTATCCATGCTTGC & 273 \\
\hline & R: GGAAGCTGGAGCCAGGTGTAG & \\
\hline 14 & F: GCTGTTGCCACACATCTTGAG & 317 \\
\hline & R: ATGGCGTGATCTGCACGTGTCA & \\
\hline 15 & F: GATTTCTTCCTGCAGCCTCTG & 292 \\
\hline & R: TGGAAACCTACACCACСТCTC & \\
\hline 16 & F: CAGATGTGCACAGGATAGTTC & 428 \\
\hline & R: GTGAGAGGTGGAGAGAATGAG & \\
\hline 17 & F: СТСАТТСТСТССАССТСТСАС & 413 \\
\hline & R: TATTGAGCACCTAGCACGTGC & \\
\hline 18 & F: CATGTTGAGCTGTACCTCACC & 361 \\
\hline & R: ACTTGGGTTAGGACTGGATGC & \\
\hline 19 & F: AGTAGAGATAGGGCTTAGCCG & 420 \\
\hline & R: CACTCCATTCATGCCAGTAGG & \\
\hline 20 & F: GAAATGGATGGTCAGAGCGG & 239 \\
\hline & R: GTGGTCCCTTCAGCTACTTC & \\
\hline 21 & F: AGAGTACAGAGTGTACCCAG & 331 \\
\hline & R: GTGAGTATCACTGCCAAGTG & \\
\hline 22 & F: AAATGGTGCTCCTGGTGGGA & 492 \\
\hline & R: GACGTTTTGCACACTGTTCC & \\
\hline 23 & F: GAGCCATCATCATGCTACTG & 603 \\
\hline & R: TCCAGCTGGGTGAAACCTCA & \\
\hline 24 & F: TTCTGGAAACTACCTCTCTATGTC & 341 \\
\hline & R: ATACAATATGACCTCAGGTCTCAC & \\
\hline 25 & F: GTGTCATCTTCCTCTACTCC & 370 \\
\hline & R: CTTCAAAGGTCCCACTAGCA & \\
\hline 26 & F: TGAAGGAAGAGAGGGACCTG & 443 \\
\hline & R: GTGACTCTGACCTATAGTGG & \\
\hline 27 & F: CCATCTTGTGTGAAGTCTTAGAG & 255 \\
\hline & R: CCTTTGGCCTAAACTCCATGAA & \\
\hline 28 & F: TGGAAAGAGAGATGGAAGGTAG & 521 \\
\hline & R: AGCACACTTGTACTGCAGCTG & \\
\hline 29 & F: CTCCAGGATCAGCATCATCC & 436 \\
\hline & R: CAGAGACTGTGTCAGAGCTTG & \\
\hline 30 & F: GCAGGAACAGGCTTCCTATC & 618 \\
\hline & R: CTCCATAGAAGTCCTGCTTTCC & \\
\hline 31 & F: GAAAGCAGGACTTCTATGGAG & 343 \\
\hline & R: GAGCAAACACAGGTCTAGACTC & \\
\hline
\end{tabular}

cation cycle consisted of a denaturation step at $94^{\circ} \mathrm{C}$, an annealing step at $59^{\circ} \mathrm{C}$, and an extension step at $72^{\circ} \mathrm{C}$ for $30 \mathrm{~s}$ each, followed by a final extension step for $10 \mathrm{~min}$ at $72^{\circ} \mathrm{C}$ and cooling to $4^{\circ} \mathrm{C}$. The amplification products were then run on $1.5 \%$ agarose gels and purified using QIAEX II gel extraction kit (QIAGEN Santa Clara, CA, USA). Purified amplification products were directly sequenced using the ABI 377 Prism Automated DNA Sequencer. DNA sequences were aligned using ABI Sequence Navigator software.

Once a sequence variant was identified in a sample, its presence was confirmed by fresh reamplification and resequencing of the culprit exon from the patient sample on another day. If the DNA change, which was usually a singlenucleotide polymorphism (SNP), affected a restriction endonuclease recognition site, restriction fragment length polymorphism analysis would be used as the basis of a rapid method to genotype the specific SNP for the purposes of determining allele and genotype frequencies in various ethnic groups, and for studies of association with plasma HDL cholesterol. In contrast, if the DNA change or SNP did not affect a restriction endonuclease recognition site, genotypes would be inferred from electropherogram traces from direct genomic DNA sequencing to determine allele and genotype frequencies in Caucasians only.

\section{Statistical analysis}

The significance of deviations of the observed genotype frequencies from those predicted by the Hardy-Weinberg equations were evaluated with chi-square tests. SAS (Version 6.12) was used for statistical comparisons involving plasma lipoproteins (SAS/STAT guide). Associations with plasma lipoproteins were assessed using an amino acid polymorphism that had sufficient heterozygosity or information content, thus ensuring sufficient numbers of subjects with each genotype for parametric statistical analysis. To test whether common variation in $A B C C 6$ was associated with variation in plasma HDL cholesterol, we thus genotyped the $A B C C 6 \mathrm{R}>\mathrm{Q} 1268$ polymorphism in a previously reported normolipidemic Inuit sample (Ringpfeil et al. 2000). We assumed a dominant model for Q1268, in which the genotype variable was set at 0 for subjects with R1268/ R1268 genotype and 1 for subjects with the Q1268/R1268 and Q1268/Q1268 genotype. Covariates in the ANOVA were age, sex, body mass index (BMI), and the presence of current cigarette smoking (Ringpfeil et al. 2000). The proportion of variation in a plasma lipoprotein concentration from each covariate was estimated from partial regression coefficients.

\section{Results}

Intron-exon boundaries of $A B C C 6$ and primers for genomic sequencing

Intron-exon boundaries were identified for 31 exons (Table 1). 
A rare $A B C C 6$ mutation in PXE with dyslipidemia

The sequencing strategy outlined earlier resulted in the identification of homozygosity for a novel ABCC6 mutation in the PXE subject with dyslipidemia, namely, R1164X (OMIM 603234.0013). This mutation was absent from 446 control alleles from 223 subjects of all ethnic groups. No other mutations were found (Le Saux et al. 2000; Bergen et al. 2000; Ringpfeil et al. 2000, 2001).

\section{Common amino acid variants in $A B C C 6$}

DNA from eight subjects with FHA was sequenced, resulting in the identification of two common amino acid variants in $A B C C 6$, namely, $\mathrm{V}>\mathrm{A} 614$ in exon 14 and $\mathrm{R}>\mathrm{Q} 1268$ in exon 27 (Table 2). Restriction analysis with endonucleases TaqI and MspI for V>A614 and R>Q1268, respectively, was used to determine the genotype and allele frequencies in the normolipidemic ethnic samples. The ABCC6 $\mathrm{V}>\mathrm{A} 614$ and $\mathrm{R}>\mathrm{Q} 1268$ polymorphisms were each polymorphic in all ethnic groups (Table 2).

\section{Common silent variants in $A B C C 6$}

The sequencing strategy outlined earlier resulted in the identification of many common silent variants in $A B C C 6$ (Table 2). Although none of these altered a naturally occurring restriction endonuclease recognition site, genotypes were easily determined from electropherogram tracings of genomic DNA sequences of the individual exons. This allowed for calculation of the genotype and allele frequencies in Caucasians only. None of the genotype frequencies for any polymorphism shown in Table 2 deviated from the expectations of the Hardy-Weinberg equation in any study sample.
Atypical sequence variants: a pseudogene for $A B C C 6$ ?

We observed disparities in the $A B C C 6$ genomic DNA sequence from the screening sample and sequences that had been previously published. Allele frequencies of these polymorphisms were each 0.5 from a total of 34 alleles from normolipidemic subjects, and all subjects were heterozygotes. Seven of these monomorphic heterozygous polymorphisms changed the amino acid sequence: namely, $\mathrm{A}>\mathrm{T} 78$, $\mathrm{E}>\mathrm{K} 125, \mathrm{~A}>\mathrm{V} 158, \mathrm{R}>\mathrm{G} 265, \mathrm{~K}>\mathrm{E} 281, \mathrm{I}>\mathrm{V} 319$, and $\mathrm{A}>\mathrm{T} 360$, and one of them, $\mathrm{Q}>\mathrm{X} 378$, encoded a premature termination. Taken together, the results suggest the presence of a related gene, or pseudogene, for $A B C C 6$, which shares homology with the first nine exons, and also has notable amino acid differences compared with the reference $A B C C 6$ gene sequence, culminating with premature termination at codon 378 .

Association of $A B C C 6 \mathrm{R}>\mathrm{Q} 1268$ with plasma lipoprotein variation

Table 3 shows baseline features of the Inuit sample studied for association of $A B C C 6 \mathrm{R}>\mathrm{Q} 1268$ genotype with plasma lipoprotein traits. Men and women differed significantly for all variables except total and LDL cholesterol.

Table 4 shows genotype distribution and allele frequencies for $A B C C 6 \mathrm{R}>\mathrm{Q} 1268$ in the Inuit sample overall and according to gender. There was no significant deviation of any genotype frequency from the Hardy-Weinberg expectation.

Analysis of variance revealed that the ABCC6 $\mathrm{R}>\mathrm{Q} 1268$ genotype was a determinant of HDL cholesterol and triglyceride concentration (Table 5). Age was a determinant of total cholesterol, HDL, LDL, and apo B; sex was a determinant of HDL cholesterol and apo AI; and BMI

Table 2. $A B C C 6$ sequence polymorphisms

\begin{tabular}{lllll}
\hline Exon & Nucleotide & Amino acid & Allele frequencies & \\
\hline 10 & $1256 \mathrm{~T}>\mathrm{C}$ & $\mathrm{N} 411$ & $1256 \mathrm{C}$ & 0.42 in Caucasians \\
& $1268 \mathrm{G}>\mathrm{A}$ & $\mathrm{V} 415$ & $1268 \mathrm{~A}$ & 0.42 in Caucasians \\
14 & $1864 \mathrm{~T}>\mathrm{C}$ & $\mathrm{V}>\mathrm{A} 614^{\mathrm{a}}$ & $\mathrm{A} 614$ & 0.17 in Chinese \\
& & & 0.27 in Oji-Cree \\
& & & 0.32 in South Asians \\
& & & 0.41 in Africans \\
& & & 0.45 in Caucasians \\
15 & $1913 \mathrm{G}>\mathrm{C}$ & $\mathrm{T} 630$ & $1913 \mathrm{C}$ & 0.56 in Inuit \\
& $1919 \mathrm{C}>\mathrm{A}$ & $\mathrm{H}>\mathrm{Q} 632$ & $\mathrm{Q} 632$ & 0.40 in Caucasians \\
19 & $2513 \mathrm{C}>\mathrm{T}$ & $\mathrm{A} 830$ & $2513 \mathrm{~T}$ & 0.40 in Caucasians \\
24 & R1164X & $\mathrm{X} 1164$ & 0.08 in Caucasians \\
27 & $3513 \mathrm{C}>\mathrm{T}$ & $\mathrm{R}>\mathrm{Q} 1268^{\mathrm{a}}$ & $\mathrm{Q} 1268$ & Absent from 223 samples \\
& & & 0.04 in Africans \\
& & & 0.06 in Chinese \\
& & & 0.14 in Oji-Cree \\
& & & 0.16 in South Asians \\
28 & & & 0.17 in Inuit \\
& & & 0.30 in Caucasians \\
& & & 0.03 in Caucasians
\end{tabular}

${ }^{\mathrm{a}}$ These SNPs were determined in several ethnic groups because of ease of analysis 
Table 3. Baseline clinical and biochemical features (mean \pm SD) for Inuit

\begin{tabular}{lllll}
\hline & Overall & Male & Female & $P$ value $^{\text {a }}$ \\
\hline$N$ & 216 & 97 & 119 & \\
Age (years) & $35.5 \pm 14.6$ & $32.7 \pm 14.6$ & $37.8 \pm 14.3$ & $<0.05$ \\
BMI $\left(\mathrm{kg} / \mathrm{m}^{2}\right)$ & $26.7 \pm 4.4$ & $25.9 \pm 4.1$ & $27.3 \pm 4.6$ & $<0.05$ \\
Weight $(\mathrm{kg})$ & $67.4 \pm 12.1$ & $70.8 \pm 12.1$ & $64.6 \pm 11.5$ & $<0.001$ \\
Total cholesterol (mmol/L) & $4.95 \pm 1.06$ & $4.77 \pm 1.10$ & $5.09 \pm 1.00$ & $<0.05$ \\
HDL cholesterol (mmol/L) & $1.41 \pm 0.37$ & $1.34 \pm 0.33$ & $1.46 \pm 0.40$ & $<0.05$ \\
LDL cholesterol (mmol/L) & $3.04 \pm 0.91$ & $2.98 \pm 0.97$ & $3.09 \pm 0.87$ & $\mathrm{NS}$ \\
Triglycerides & $1.10 \pm 0.58$ & $0.97 \pm 0.46$ & $1.19 \pm 0.65$ & $<0.05$ \\
apo AI $(\mathrm{g} / \mathrm{L})$ & $1.64 \pm 0.23$ & $1.59 \pm 0.22$ & $1.67 \pm 0.23$ & $<0.05$ \\
apo B $(\mathrm{g} / \mathrm{L})$ & $0.95 \pm 0.26$ & $0.95 \pm 0.28$ & $0.95 \pm 0.25$ & $\mathrm{NS}$ \\
\hline
\end{tabular}

BMI, body mass index; HDL, high-density lipoprotein; LDL, low-density lipoprotein; apo, apolipoprotein; NS, not significant

${ }^{a}$ Bonferroni $\mathrm{P}$ values for between-sex differences using the $t$ test

Table 4. Genotype distribution and allele frequencies for $A B C C 6$ $\mathrm{R}>\mathrm{Q} 1268$ in Inuit

\begin{tabular}{lrllllll}
\hline & & \multicolumn{2}{c}{$A B C C 6$ genotype distribution } & \multicolumn{2}{c}{$\begin{array}{l}\text { ABCC6 allele } \\
\text { frequency }\end{array}$} \\
\cline { 3 - 5 } & & R1268/ & Q1268/ & Q1268/ & & R1268 & Q1268 \\
\hline Total & 216 & 154 & 55 & 7 & 0.84 & 0.16 \\
Males & 97 & 69 & 23 & 5 & 0.83 & 0.17 \\
Females & 119 & 85 & 32 & 2 & 0.85 & 0.15 \\
\hline
\end{tabular}

was a determinant of LDL and HDL cholesterol and triglycerides. Smoking was not a significant determinant of any lipoprotein trait in this sample.

Least squares mean $( \pm \mathrm{SE})$ plasma HDL cholesterol (adjusted for age and sex) was $1.37 \pm 0.39 \mathrm{mmol} / \mathrm{L}$ for the 154 subjects with the $A B C C 6$ R1268/R1268 genotype and $1.49 \pm 0.32 \mathrm{mmol} / \mathrm{L}$ for the 62 subjects with either the ABCC6 Q1268/R1268 or the Q1268/Q1268 genotypes (Bonferroni $P<0.05$ ). Least squares mean $( \pm \mathrm{SE}$ ) plasma triglycerides (adjusted for age and sex) were $1.16 \pm$ $0.63 \mathrm{mmol} / \mathrm{L}$ for the 154 subjects with the ABCC6 R1268/ $\mathrm{R} 1268$ genotype and $0.94 \pm 0.37 \mathrm{mmol} / \mathrm{L}$ for the 62 subjects with either the $A B C C 6$ Q1268/R1268 or the Q1268/Q1268 genotypes (Bonferroni $P<0.05$ ). Thus, the $A B C C 6 \mathrm{Q} 1268$ allele was associated with lower plasma triglycerides and higher plasma HDL cholesterol. Multivariate regression analysis indicated that the $A B C C 6 \mathrm{R}>\mathrm{Q} 1268$ genotype accounted for $11.1 \%$ of variation in plasma HDL cholesterol $(P=0.024)$ and for $11.0 \%$ of variation in plasma triglyceride $(P=0.05)$. Post hoc analyses revealed no associations with plasma apo AI (data not shown).

\section{Discussion}

We report (1) identification of a set of amplification primers for all 31 of the $A B C C 6$ exons that amplify at a single annealing temperature, allowing for optimal use of hardware; (2) identification of a rare $A B C C 6$ mutation in a subject with PXE, type IV hyperlipidemia and hypoalphalipoproteinemia; (3) identification of several
Table 5. Summary of ANOVA for quantitative traits in Inuit

\begin{tabular}{|c|c|c|c|}
\hline & & $F$ value & $P$ value \\
\hline \multicolumn{4}{|c|}{ Dependent variable: log total cholesterol } \\
\hline \multirow[t]{5}{*}{ Sources of variation: } & $A B C C 6$ genotype & 0.17 & NS (0.68) \\
\hline & Age & 29.7 & $<0.0001$ \\
\hline & Sex & 0.89 & NS $(0.35)$ \\
\hline & Smoking & 0.52 & NS (0.47) \\
\hline & BMI & 2.05 & NS (0.15) \\
\hline \multicolumn{4}{|c|}{ Dependent variable: $\log$ HDL } \\
\hline \multirow[t]{5}{*}{ Sources of variation: } & $A B C C 6$ genotype & 5.95 & 0.012 \\
\hline & Age & 19.2 & $<0.0001$ \\
\hline & Sex & 4.62 & 0.033 \\
\hline & Smoking & 3.66 & NS (0.06) \\
\hline & $\mathrm{BMI}$ & 21.2 & $<0.0001$ \\
\hline \multicolumn{4}{|c|}{ Dependent variable: $\log$ LDL } \\
\hline \multirow[t]{5}{*}{ Sources of variation: } & $A B C C 6$ genotype & 0.07 & NS (0.78) \\
\hline & Age & 19.2 & $<0.0001$ \\
\hline & Sex & 0.01 & NS (0.94) \\
\hline & Smoking & 0.00 & NS (0.98) \\
\hline & BMI & 4.31 & 0.039 \\
\hline \multicolumn{4}{|c|}{ Dependent variable: log triglycerides } \\
\hline \multirow[t]{5}{*}{ Sources of variation: } & $A B C C 6$ genotype & 3.93 & 0.045 \\
\hline & Age & 0.01 & NS (0.93) \\
\hline & Sex & 3.02 & NS (0.08) \\
\hline & Smoking & 1.98 & NS (0.16) \\
\hline & BMI & 20.0 & $<0.0001$ \\
\hline \multicolumn{4}{|c|}{ Dependent variable: $\log$ apo AI } \\
\hline \multirow[t]{5}{*}{ Sources of variation: } & ABCC6 genotype & 0.03 & NS $(0.85)$ \\
\hline & Age & 2.94 & NS (0.09) \\
\hline & Sex & 5.03 & 0.027 \\
\hline & Smoking & 0.77 & NS $(0.38)$ \\
\hline & $\mathrm{BMI}$ & 1.67 & NS $(0.20)$ \\
\hline \multicolumn{4}{|c|}{ Dependent variable: $\log$ apo B } \\
\hline \multirow[t]{5}{*}{ Sources of variation: } & $A B C C 6$ genotype & 0.74 & NS (0.39) \\
\hline & Age & 12.6 & 0.0005 \\
\hline & Sex & 0.37 & NS $(0.54)$ \\
\hline & Smoking & 0.16 & NS (0.69) \\
\hline & BMI & 2.65 & NS (0.11) \\
\hline
\end{tabular}

ANOVA, analysis of variance; BMI, body mass index; HDL, highdensity lipoprotein; LDL, low-density lipoprotein; apo, apolipoprotein; NS, not significant

common amino acid variants and silent nucleotide variants in $A B C C 6$, with a range of allele frequencies across ethnic groups; (4) evidence consistent with a pseudogene encoding 9 exons that share sequence homology with $A B C C 6$; and (5) association of the common ABCC6 $\mathrm{R}>\mathrm{Q} 1268$ variant with plasma triglyceride and HDL cholesterol in Inuit. The 
$A B C C 6$ Q1268 allele was associated with lower plasma triglycerides and higher plasma HDL cholesterol, suggesting that $A B C C 6$ may determine plasma lipoproteins.

The results indicate that sequencing directly from genomic DNA and analysis of attributes of detected SNPs such as allele frequency, genotype frequency, and deviations from Hardy-Weinberg equilibrium can help define regions that have attributes of pseudogenes or gene duplication. Such results would not necessarily arise from experiments that analyzed cDNA only, indicating the power to obtain additional molecular information afforded by sequencing directly from genomic DNA.

It is not clear whether the plasma lipoprotein abnormalities in our single PXE patient were attributable to his rare ABCC6 mutation. Lipoprotein profiles were not reported from other subjects with this mutation (Neldner 1988; Renie et al. 1984). In general, plasma lipid profiles have not been very carefully characterized in most patients with PXE. Cross-sectional studies involving a total of $>100$ PXE subjects have suggested a prevalence of both hypertriglyceridemia (Neldner 1988; Renie et al. 1984) and depressed HDL cholesterol (Neldner 1988) that is approximately twice as high as in the general population. Taken together with the association of the $A B C C 6 \mathrm{R}>\mathrm{Q} 1268$ polymorphism with variation in plasma triglycerides and HDL cholesterol, ABCC6 may be a determinant of variation in plasma lipoproteins.

$A B C C 6$ belongs to the $\mathrm{ABC}$ gene subfamily $\mathrm{C}$, which includes $A B C C 1-5, C F T R, A B C C 8$, and $A B C C 9$ (encoding the sulfonylurea receptor) (Borst et al. 2000). The exact biological function of $A B C C 6$ is unknown, although it may transport hydrophobic xenobiotics (Borst et al. 2000). In addition, the mechanism underlying development of PXE from mutations in the $A B C C 6$ transmembrane receptor gene product is unknown. A role for the $A B C C 6$ gene product in lipid transport and metabolism is possible for several reasons. For instance, $A B C C 6$ shares considerable homology of both predicted structure and domain organization compared with other members of the $A B C$ gene family, of which at least 10 have been implicated to be involved in cellular lipid transport (Borst et al. 2000). However, in contrast to other members of the $\mathrm{ABC}$ gene family, expression of the $A B C C 6$ gene product appears not to be regulated in vitro by plasma lipoproteins.

The common $A B C C 6 \mathrm{R}>\mathrm{Q} 1268$ variant occurs within the 3 '-intracytoplasmic domain of $A B C C 6$ (Le Saux et al. 2000; Bergen et al. 2000; Ringpfeil et al. 2000, 2001). Although originally proposed to be a disease mutation, subsequent work indicated that $A B C C 6 \quad \mathrm{R}>\mathrm{Q} 1268$ was a common polymorphism (Germain et al. 2000), which is consistent with our findings. Our present analysis provides evidence that common variation in $A B C C 6$ is associated with variation in quantitative plasma lipoprotein traits. There is no explanation at present for how this common variant might affect plasma lipoprotein metabolism. Indeed, the observed association might be related to linkage disequilibrium with a functional variant at or near the $A B C C 6$ locus, such as the closely linked $A B C C 1$ and $P M 5$ genes and/or other unknown genes on 16p13.1 (Lee et al. 2001). How- ever, the $A B C C 6$ locus is distinct from the reported chromosome 16q locus linked to familial combined hyperlipoproteinemia (Aouizerat et al. 1999).

In summary, we defined primers to amplify the $A B C C 6$ coding region. We used these primers in direct genomic DNA sequencing to identify a nonsense mutation in a subject with PXE and dyslipidemia. We found several SNPs within the coding sequence of $A B C C 6$, of which one was associated with variation in plasma lipoproteins in a normolipidemic sample. The results suggest that $A B C C 6$ mutations, both rare and common, are associated with variation in plasma lipoproteins.

Acknowledgments We thank Ms. Carol Anderson and Ms. Pearl Campbell for their expert assistance. This work was supported by grants from the CIHR (Canada, \#MT13430), the Canadian Genetic Diseases Network, and the Blackburn Group. Dr. Hegele holds a Canada Research Chair in Human Genetics and is a Career Investigator (\#CI-2979) of the Heart and Stroke Foundation of Ontario. Dr. Young is a Senior Scientist of the CIHR. Ms. Near was a participant in the Waterloo University Co-operative Education Program.

\section{References}

Aouizerat BE, Allayee H, Cantor RM, Dallinga-Thie GM, Lanning CD, de Bruin TW, Lusis AJ, Rotter JI (1999) Linkage of a candidate gene locus to familial combined hyperlipidemia: lecithin:cholesterol acyltransferase on 16q. Arterioscler Thromb Vasc Biol 19:27302736

Berge KE, Tian H, Graf GA, Yu L, Grishin NV, Schultz J, Kwiterovich P, Shan B, Barnes R, Hobbs HH (2000) Accumulation of dietary cholesterol in sitosterolemia caused by mutations in adjacent ABC transporters. Science 290:1771-1775

Bergen AA, Plomp AS, Schuurman EJ, Terry S, Breuning M, Dauwerse H, Swart J, Kool M, van Soest S, Baas F, ten Brink JB, de Jong PT (2000) Mutations in ABCC6 cause pseudoxanthoma elasticum. Nat Genet 25:228-231

Bodzioch M, Orso E, Klucken J, Langmann T, Bottcher A, Diederich W, Drobnik W, Barlage S, Buchler C, Porsch-Ozcurumez M, Kaminski WE, Hahmann HW, Oette K, Rothe G, Aslanidis C, Lackner KJ, Schmitz G (1999) The gene encoding ATP-binding cassette transporter 1 is mutated in Tangier disease. Nat Genet 22:347-351

Borst P, Zelcer N, van Helvoort A (2000) ABC transporters in lipid transport. Biochim Biophys Acta 1486:128-144

Brooks-Wilson A, Marcil M, Clee SM, Zhang LH, Roomp K, van Dam $\mathrm{M}, \mathrm{Yu} \mathrm{L}$, Brewer C, Collins JA, Molhuizen HO, Loubser O, Ouelette BF, Fichter K, Ashbourne-Excoffon KJ, Sensen CW, Scherer S, Mott S, Denis M, Martindale D, Frohlich J, Morgan K, Koop B, Pimstone S, Kastelein JJ, Hayden MR (1999) Mutations in $\mathrm{ABC1}$ in Tangier disease and familial high-density lipoprotein deficiency. Nat Genet 22:336-345

Brousseau ME, Schaefer EJ, Dupuis J, Eustace B, Van Eerdewegh P, Goldkamp AL, Thurston LM, FitzGerald MG, Yasek-McKenna D, O'Neill G, Eberhart GP, Weiffenbach B, Ordovas JM, Freeman MW, Brown RH Jr, Gu JZ (2000) Novel mutations in the gene encoding ATP-binding cassette 1 in four Tangier disease kindreds. J Lipid Res 41:433-441

Clee SM, Zwinderman AH, Engert JC, Zwarts KY, Molhuizen HO, Roomp K, Jukema JW, van Wijland M, van Dam M, Hudson TJ, Brooks-Wilson A, Genest J Jr, Kastelein JJ, Hayden MR (2001) Common genetic variation in $A B C A 1$ is associated with altered lipoprotein levels and a modified risk for coronary artery disease. Circulation 103:1198-1205

Germain DP, Perdu J, Remones V, Jeunemaitre X (2000) Homozygosity for the $\mathrm{R} 1268 \mathrm{Q}$ mutation in MRP6, the pseudoxanthoma elasticum gene, is not disease-causing. Biochem Biophys Res Commun 274:297-301 
Hegele RA, Young TK, Connelly PW (1997) Are Canadian Inuit at increased genetic risk for coronary heart disease? J Mol Med 75:364 370

Klucken J, Buchler C, Orso E, Kaminski WE, Porsch-Ozcurumez M, Liebisch G, Kapinsky M, Diederich W, Drobnik W, Dean M, Allikmets R, Schmitz G (2000) ABCG1 (ABC8), the human homolog of the Drosophila white gene, is a regulator of macrophage cholesterol and phospholipid transport. Proc Natl Acad Sci USA 97:817-822

Lee MH, Lu K, Hazard S, Yu H, Shulenin S, Hidaka H, Kojima H, Allikmets R, Sakuma N, Pegoraro R, Srivastava AK, Salen G, Dean M, Patel SB (2001) Identification of a gene, $A B C G 5$, important in the regulation of dietary cholesterol absorption. Nat Genet 27:79-83

Le Saux O, Urban Z, Tschuch C, Csiszar K, Bacchelli B, Quaglino D, Pasquali-Ronchetti I, Pope FM, Richards A, Terry S, Bercovitch L, de Paepe A, Boyd CD (2000) Mutations in a gene encoding an ABC transporter cause pseudoxanthoma elasticum. Nat Genet 25:223-227

Neldner KH (1988) Pseudoxanthoma elasticum. Clin Derm 6:83-92

Remaley AT, Rust S, Rosier M, Knapper C, Naudin L, Broccardo C, Peterson KM, Koch C, Arnould I, Prades C, Duverger N, Funke H, Assman G, Dinger M, Dean M, Chimini G, Santamarina-Fojo S, Fredrickson DS, Denefle P, Brewer HB Jr (1999) Human ATP binding cassette transporter $1(\mathrm{ABC} 1)$ : genomic organization and identification of the genetic defect in the original Tangier disease kindred. Proc Natl Acad Sci USA 96:12685-12690

Renie WA, Pyeritz RE, Combs J, Fine SL (1984) Pseudoxanthoma elasticum: high calcium intake in early life correlates with severity. Am J Med Genet 19:235-244

Ringpfeil F, Lebwohl MG, Christiano AM, Uitto J (2000) Pseudoxanthoma elasticum: mutations in the MRP6 gene encoding a transmembrane ATP-binding cassette (ABC) transporter. Proc Natl Acad Sci USA 97:6001-6006

Ringpfeil F, Nakano A, Uitto J, Pulkkinen L (2001) Compound heterozygosity for a recurrent $16.5-\mathrm{kb}$ Alu-mediated deletion mutation and single-base-pair substitutions in the $A B C C 6$ gene results in pseudoxanthoma elasticum. Am J Hum Genet 68:642-652

Rust S, Rosier M, Funke H, Real J, Amoura Z, Piette JC, Deleuze JF, Brewer HB, Duverger N, Denefle P, Assmann G (1999) Tangier disease is caused by mutations in the gene encoding ATP-binding cassette transporter 1. Nat Genet 22:352-355

SAS/STAT guide for personal computers (1987) SAS Institute, Cary, NC

Wang J, Burnett JR, Near S, Young K, Zinman B, Hanley AJ, Connelly PW, Harris SB, Hegele RA (2000) Common and rare $A B C A 1$ variants affecting plasma HDL cholesterol. Arterioscler Thromb Vasc Biol 20:1983-1989 